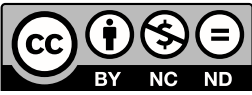

Estudos Teológicos foi licenciado com uma Licença Creative Commons Atribuição - NãoComercial - SemDerivados 3.0 Não Adaptada

http://dx.doi.org/10.22351/etv59i2.3816

\title{
À LUZ DA CRÍTICA HISTÓRICA: SOBRE O MÉTODO HISTÓRICO-CRÍTICO NO ESTUDO DA BÍBLIA ${ }^{1}$ \\ In the light of historical criticism: \\ about the use of the historical-critical method in biblical studies
}

\section{Haroldo Reimer ${ }^{2}$ Ivoni Richter Reimer ${ }^{3}$}

Nem todas as verdades são para todos os ouvidos. (Umberto Eco)

Resumo: O artigo apresenta apontamentos gerais sobre algumas contribuições no campo das Humanidades para a emergência da crítica metódica de tradições e textos bíblicos e sua culminância no método histórico-crítico no campo dos estudos bíblicos. Busca-se também apresentar sinteticamente os passos desse método, indicando-se para algumas limitações do mesmo e esforços interdisciplinares em sua utilização.

Palavras-chave: Método histórico-crítico. Hermenêutica. Crítica histórica.

Abstract: This article presents general appointments about some contributions in Humanities which favored the emergency of methodic critics coming to the historical critical method in the field of biblical studies. We also try to present in a short way the steps of this method, indicating as for some limitations as well for necessary interdisciplinary efforts by using the method.

Keywords: Historical Critical Method. Hermeneutics. Historical criticism.

\section{Introdução}

O presente artigo objetiva contribuir para o uso do método histórico-crítico em exercícios exegéticos para melhor compreender textos bíblicos. Para tal, inicialmente apresentamos considerações sobre a emergência de reflexões teóricas para a constituição de um espírito crítico de suas próprias fontes, a iniciar com o humanismo re-

1 O artigo foi recebido em 28 de agosto de 2019 e aprovado em 26 de novembro de 2019 com base nas avaliações dos pareceristas ad hoc.

2 Doutor. Universidade Estadual de Goiás, Anápolis, GO. E-mail: haroldo.reimer@gmail.com

3 Doutora. Pontifícia Universidade Católica de Goiás, Goiânia, GO. E-mail: ivonirr@gmail.com 
nascentista. Destacamos alguns protagonistas que, com suas críticas e reflexões, ajudaram a forjar uma metodologia para reconstruir as realidades históricas por trás dos textos bíblicos. Num segundo momento, delineamos alguns passos metodológicos do método e refletimos sobre suas contribuições, indicando também para limitações e a necessidade do trabalho interdisciplinar também na exegese.

\section{Para uma genealogia do método histórico-crítico e suas limitações}

Em perspectiva genealógica, um tratamento histórico-crítico de textos bíblicos está relacionado com postulados e práticas de determinados protagonistas no âmbito do renascentismo humanista, a partir do século $\mathrm{XV}^{4}$ No Ocidente, após um milênio de domínio do cristianismo por meio de suas estruturas e sua língua franca, o latim, começam a emergir personagens com elementos de crítica às fontes e tradições estruturantes desse sistema medieval, fortemente dominado pela instituição igreja. Esse potencial de crítica às fontes valeu-se, na maioria das vezes, da maestria no domínio das línguas grega e latina em seus vários estágios, bem como da volta às formas da arte típicas do período clássico da antiguidade grega e romana.

Um desses personagens emblemáticos foi o italiano Lorenzo Valla (14071457). Valla foi um precursor do humanismo renascentista, filósofo, jurista e filólogo. Um de seus enfoques era a crítica à escolástica. Como bom manejador do grego e do latim, propôs várias correções a traduções e interpretações de textos de Aristóteles e outros autores da antiguidade clássica. Proporcionou-lhe grande notoriedade a publicação, em 1439, do opúsculo De Falso Credita et Ementita Constantini Donatione Declamatio, pelo qual apresentou indícios e provas de que o documento latino da famosa Doação de Constantino, segundo a qual insígnias do poder imperial teriam sido transmitidas ao papado, era um documento que, pela análise filológica acurada, deveria datar de vários séculos posteriores a Constantino, devendo ser visto, portanto, como uma falsificação. A filologia clássica serviu aqui como elemento de crítica a fontes de sustentação da estrutura do domínio eclesiástico, ensejando inícios de ruptura com o mesmo.

No mesmo impulso de crítica filológica situa-se Desidério Erasmo de Rotterdã (1467-1536). Para além de sua obra mais famosa, O Elogio da loucura, esse autor nascido nos Países Baixos e educado na tradição agostiniana, embora crítico da vida monástica, ganhou notoriedade pela publicação de uma edição crítica do Novo Testamento em grego, o Novum Instrumentum Omne, diligenter ab Erasmo Rot. Recognitum et Emendatum (1516). Utilizando-se do acesso a manuscritos trazidos à luz naquela época, Erasmo comparou vários manuscritos, estabeleceu um deles como textos receptus (texto-base) e, além de uma tradução para o latim, fez constar em

4 Informações acerca desses protagonistas, abaixo resumidamente apresentados, ver em VOLKMANN, Martin; DOBBERAHN, Friedrich Erich; CÉSAR, Ely Éser Barreto. Método Histórico-critico. São Paulo: CEDI, 1992; FITZMYER, Joseph A. A interpretação da Escritura: em defesa do método histórico-crítico. São Paulo: Loyola, 2011. 
notas as diferenças textuais encontradas entre as várias versões. Com esse movimento de filologia comparativa, estabeleceu uma crítica à versão latina da Bíblia, a Vulgata, que durante muito tempo foi, e por séculos continuou a ser, a edição oficial da igreja romana. Assim procedendo, fez emergir os indícios de crítica e de dúvida em relação a esse documento eclesiástico oficial. Ora, se não havia concordância entre os manuscritos gregos, muito mais antigos e mais próximos do suposto original, como poderia haver confiança plena na fidedignidade do texto latino oficial? O gérmen da dúvida estava posto!

$\mathrm{Na}$ esteira dessa contribuição inaugural está situado hoje o enorme trabalho de Nestle e Aland com a edição do Novum Testamentum Graece. ${ }^{5}$ A obra serve de material para o acesso ao chamado texto original do Novo Testamento, especialmente para a realização do primeiro passo metodológico da tradução provisória e da crítica textual, que tem como objetivo buscar delimitar aquele que seria o texto mais original, bem como mapear as diferenças nos manuscritos e nas versões, abrindo, assim, o horizonte para as diferenças no caminho da transmissão do texto.

Dentro do movimento mais amplo do humanismo renascentista dos séculos XV e XVI deve-se situar o movimento da Reforma protestante, que teve no monge agostiniano e reformador Martim Lutero seu expoente maior. Os objetivos desse movimento são diversos, cabendo ressaltar que o esforço de tradução da Bíblia para o alemão feito por Lutero ensejou uma série de trabalhos adicionais em termos de filologia clássica. Em concomitância e concordância com a sua ênfase no princípio Sola Scriptura, Lutero colocou foco no sentido literal do texto bíblico, distanciando-se em grande medida da leitura alegórica predominante na época. Com isso, realizou um movimento rumo à busca pela historicidade do texto sagrado, estando, contudo, ainda longe de uma crítica histórica do texto, o que viria a se materializar somente séculos depois. Neste sentido, expressa-o muito bem Martin Volkmann ${ }^{6}$, no seu ainda importante trabalho sobre o método histórico-crítico:

A Reforma, com o postulado de que a Escritura é a única fonte da Revelação, coloca-a como centro das atenções e desencadeia com isso o surgimento da ciência bíblica. Tal concentração na Escritura leva, por outro lado, a um posicionamento crítico frente à Escritura que desembocará na análise histórico-crítica da Bíblia.

Esse posicionamento crítico iniciado na Renascença percorreu um árduo e tortuoso caminho que apresenta uma série de pesquisadores, tais como Semler, Flacius, Grotius e outros. ${ }^{7}$

Importante parece-nos destacar que a ruptura da consciência vinculada à Escritura como fonte de revelação e verdade precisou passar por canais reflexivos que hoje estão situados mais no campo da Filosofia do que da Teologia. Destacamos o fran-

5 NESTLE, Eberhard Erwin; ALAND, Barbara e Kurt (Eds.). Novum Testamentum Graece. 27. rev. Aufl., 2. Druck. Stuttgart: Deutsche Bibelgesellschaft, 1994. Essa obra já está em sua 28. edição.

6 VOLKMANN; DOBBERAHN; CÉSAR, 1992, p. 12.

7 Suas contribuições constam em VOLKMANN; DOBBERAHN; CÉSAR, 1992. 
cês Renée Descartes (1596-1650), que, em diálogo crítico com o ceticismo pirrônico, rompeu essa cadeia cética rumo a uma consciência crítica, que, em teoria, se propõe a colocar a dúvida sobre tudo aquilo que acessa a consciência: "Se eu duvido, eu penso, se eu penso, eu existo". Com esse slogan e com sua obra Regras para a condução do Espirito (1628), Descartes colocou as bases para uma metodologia científica, que passa pela análise detalhada das partes rumo a uma síntese como resultado e expressão do trabalho científico crítico, simbolizando a transição do paradigma medieval para o moderno. Gradativamente esse posicionamento crítico foi sendo recepcionado nas discussões teológicas nas academias em que havia abertura para a chamada "alta crítica".

Se Lutero, com o princípio protestante do Sola Scriptura, colocou a Bíblia no centro dos estudos com a ênfase no sentido literal, as igrejas protestantes, notadamente com os contrapontos da ortodoxia protestante, precisavam promover um constante reforço institucional da autoridade da Bíblia em termos de fundamento da verdade e da revelação, mantendo um princípio fideísta, que sempre de novo sobrepunha aos textos elementos de dogmática teológica como sentido geral do texto, constituindo, assim, reiterados entraves para uma crítica mais profunda e radical dos textos escriturísticos. Alguns protagonistas como Mathias Flacius Illyricus (1520-1575) e Johann Semler (1725-1791) merecem menção nesse contexto, por representarem, por um lado, em sua metodologia, um foco claro no sentido literal do texto, mas, por outro, manterem-se ainda aderentes à dogmática. ${ }^{8}$

De grande importância são os trabalhos de Hugo Grotius (1583-1645), compilados em suas Annotationes in Novum Testamentum e Annotationes in Vetus Testamentum. Como grande filólogo clássico, em diálogo aberto com importantes eventos e personagens de sua época, como a sua contribuição para a Paz da Westfália, Grotius diferenciou o Antigo e o Novo Testamento enquanto grandezas canônicas distintas em sua origem, focou no sensus primarius dos textos e colocou ambas as coleções de textos dentro do contexto da literatura universal, portanto no horizonte do surgimento histórico dos textos. Importante, na perspectiva de Grotius, é que os textos bíblicos devem ser vistos como emergências em momentos históricos distintos, tendo, portanto, uma base histórica que deve ser investigada, derivando-se daí também intencionalidades do próprio texto em seu contexto originário.

Em todos os sentidos, o século XIX foi o contexto em que algo como um método histórico-crítico teve condições de amadurecimento. Foi o século da desconstrução por excelência, tendo em Nietzsche, Marx e Feuerbach arautos de grande destaque nessa seara no sentido de que história e suas produções culturais e ideológicas têm condições materialistas de produção e emergência, carecendo de acurada análise para compreensão de seus sentidos, sobretudo em seus momentos originários. Alguns movimentos são dignos de nota para a compreensão desses desenvolvimentos.

Primeiramente é importante destacar que o século XIX é o tempo da publicação da obra de Charles Darwin, A Origem das Espécies, trazida à lume em 1859.9

\footnotetext{
8 Ver VOLKMANN; DOBBERAHN; CÉSAR, 1992; FITZMEYER, 2011.

9 DARWIN, Charles. A origem das espécies. Trad. Eduarco Fonseca. São Paulo: Hemus, [s.d.].
} 
Essa obra é caudatária de muitas discussões entre pesquisadores a respeito da "idade" do ser humano, contribuindo para superar a noção até então existente da chamada "idade adâmica", que se fundamentava nas genealogias bíblicas para esse cálculo. Com Darwin, o conceito de historicidade ou existência histórica sofreu um colossal alargamento temporal, sendo importante para a emergência de uma disciplina chamada História, que, por seu turno, se desvinculou dos postulados de uma filosofia da história especulativa como a de Hegel para buscar elucidar a história "como de fato foi", considerando efetivamente o lapso temporal alargado. Nesse movimento, o cálculo do tempo pautado pelas genealogias bíblicas ficou superado!

$\mathrm{Na}$ emergência de um conjunto de reflexões epistemológicas para o campo da História deve-se, em segundo lugar, fazer menção às contribuições de Leopold von Ranke (1795-1886) e sua busca pela reconstrução da história como "de fato foi". O conceito de historismo ou historicismo ganhou aqui em maturidade, com capacidade para influenciar os estudos sobre as origens e os sentidos dos textos bíblicos. No mesmo contexto, o pesquisador alemão Ernst Troeltsch (1865-1923), em seu texto Sobre o Método Histórico e Dogmático da Teologia ${ }^{10}$, deu destaque para três elementos que deveriam orientar os estudos históricos relacionados à Teologia e também à Bíblia: a crítica, que deve se deixar conduzir pela dúvida metódica; a inter-relação entre o mundo fenomênico e suas expressões ideológicas e a analogia, que deve ser o elemento-chave para o estudo dos acontecimentos históricos, buscando aferir os seus graus de probabiliade. Novos movimentos ao longo do século XX agregaram revisões e perspectivas ao historicismo desse período frutuoso, especialmente a história cultural, a história das mentalidades e a história social. As incorporações dessas discussões para o campo dos estudos bíblicos mantinham a perspectiva de dar maior credibilidade histórica para os referidos textos. Não mais era suficiente enunciar a "verdade"; ela deveria ser historicamente verificável em sua cultura material, ainda que a comprovação passasse em boa medida pela "compreensão", como um passo metodológico próprio das "Ciências do espírito" ou Humanidades. ${ }^{11}$ A busca pelo Jesus histórico, por exemplo, se situa nesse contexto de discussões. Importava reconstruir, pelos caminhos da crítica histórica, as próprias bases históricas da fé em geral e dos textos bíblicos em particular!

O terceiro movimento importante é a emergência da arqueologia bíblica ${ }^{12}$, que, na sua origem, procurou ser um conjunto de esforços para elucidar as bases materiais dos textos bíblicos, tendo, portanto, foco na cultura material dos textos sagrados, mas mantendo igualmente no horizonte a perspectiva da reconstrução material das bases

${ }^{10}$ TROELTSCH, Ernst. Über historische und dogmatische Methode in der Theologie. Theologie und Wissenschaft. Theologische Bucherei, Munique, v. 40, p. 105-127, 1971. O texto foi traduzido ao português por Milton Schwantes e publicado na forma de polígrafo.

${ }^{11}$ Ver FUNARI, Pedro Paulo. Os historiadores e a cultura material. In: PINSKY, Carla Bassanezi (Org.). Fontes históricas. 2. ed. São Paulo: Contexto, 2010. p. 81-110.

${ }^{12}$ Acerca da importância que as pesquisas arqueológicas tiveram e têm nesse processo, ver KAEFER, José Ademar. A Liberdade como condição para a Paz! As Cartas de El-Amarna e o contexto sociopolítico do Sul de Canaã. Caminhos, Goiânia, v. 17, n. 2, p. 791-808, maio/ago. 2019, com bibliografia. 
dos textos sagrados, visando à sua (maior) credibilidade em termos históricos. O lema "pá e Bíblia" era recorrente no período de ouro da arqueologia bíblica do século XIX até a Primeira Guerra Mundial, sendo muitos os protagonistas que se movimentavam em duas grandes escolas: a norte-americana, que tinha William F. Albright como elemento fundante e a escola europeia, com a inglesa Katlheen Kenyon como uma pesquisadora de destaque. Os desdobramentos foram enormes, com muitas expedições arqueológicas organizadas pelas respectivas sociedades e publicadas em seus journals. ${ }^{13}$ Os resultados, baseados nos métodos da Arqueologia como disciplina autônoma a partir desse período, não raras vezes colocavam a luz da dúvida e da crítica sobre as narrativas bíblicas. $\mathrm{O}$ confronto com a materialidade do mundo bíblico sempre mais colocava os textos na iminência da crítica e da também da dúvida. Concomitantemente, porém, a arqueologia bíblica continha também um componente de concordismo. A arqueologia bíblica posterior à criação do Estado de Israel aperfeiçoou a metodologia e se distanciou em determinados graus desse concordismo presente em muitas publicações da arqueologia bíblica cristã, que procuravam gerar concordância entre afirmações de textos bíblicos e determinados achados arqueológicos. ${ }^{14}$

Cabe ainda fazer menção aos estudos antropológicos ou etnológicos desenvolvidos durante o século XIX e que parcialmente tiveram recepção no campo da pesquisa bíblica. Tais estudos tinham o objetivo de mapear e analisar o "outro" não europeu em suas estruturas e mecanismos sociais e culturais, não raras vezes buscando comprovar a superioridade racional da cultura ocidental cristã, dentro de um paradigma da chamada antropologia evolutiva. Importante nesse contexto são os estudos sobre o mito como forma literária e suas variadas funções sociais. Vários foram os pesquisadores com seus esforços para superar um enfoque evolutivo nesse ramo das ciências humanas, passando a reconhecer que os povos em geral têm mitos como elementos fundantes de suas representações e imaginários. ${ }^{15}$ Nessa perspectiva, para os que se movimentam dentro da lógica do mito, essas narrativas são verdadeiras e instituidoras de sentido, passando a ser referência para a condução da vida pessoal e coletiva. Reconhecer isso para as outras culturas foi um passo de maturação da Antropologia, mas havia a demanda de incorporar essa perspectiva na Teologia e nos estudos bíblicos. ${ }^{16} \mathrm{Na}$ chamada "escola da história das religiões", o alemão Herman Gunkel (1862-1932) foi pioneiro em reconhecer em seus estudos sobre Gênesis e Salmos que

13 Ver RODRIGUES, Gabriella Barbosa. Arqueologia bíblica: um estudo de narrativas e discursos acerca de sua história como disciplina. Campinas, 2011; RODRIGUES, Gabriella Barbosa; FUNARI, Pedro Paulo A. Considerações sobre a trajetória inicial da arqueologia bíblica. Mosaico, Goiânia, v. 2, n. 2, p. 95-101, jul./dez. 2009.

14 Autores como Israel Finkelstein, Amihai Mazar e Neil Asher Silberman são representativos da arqueologia bíblica crítica contemporânea. Ver FINKELSTEIN, Israel; SILBERMAN, Neil Asher. A Bíblia não tinha razão. Trad. Tuca Magalhães. São Paulo: A Girafa, 2003.

15 Ver DETIENNE, Marcel. A invenção da mitologia. Rio de Janeiro: José Olympio; Brasília: UnB, 1998.

16 Sobre essa questão aqui resumidamente apresentada, ver REIMER, Haroldo. O antigo Israel. História, textos e representações. São Paulo: Fonte; Anápolis: Ed. da UEG, 2017. p. 67-88. Ver também CROATTO, José Severino. As Linguagens da Experiência Religiosa: uma introdução à fenomenologia da religião. Trad. Carlos M. V. Gutiérrez. São Paulo: Paulinas, 2001. 
essas narrativas bíblicas apresentam muitos elementos mitológicos, delimitando-os como tais em termos de gênero literário e buscando o seu lugar vivencial, bem como suas funcionalidades no contexto histórico. ${ }^{17}$ Os estudos de Martin Dibelius sobre as formas literárias do Novo Testamento e as análises de Rudolf Bultmann sobre o Jesus histórico e o Cristo da fé trouxeram essa perspectiva para o campo dos estudos do Novo Testamento. ${ }^{18}$ Para esse último, a historicidade de Jesus estava envolta em estruturas literárias de ordem mítica, as quais deveriam ser desconstruídas para chegar ao núcleo histórico num processo de desmitologização. Instalou-se, assim, uma nova tensão no campo desses estudos, que precisa ser levada a sério até como corretivo aos esforços do historicismo e da arqueologia para aferir credibilidade aos textos sagrados em termos de sua historicidade. Isso também se aplica a textos como Gênesis 1-11 ou Apocalipse 12-13, p. ex.

Para tais questionamentos obviamente deve-se trabalhar com um conceito de mito que classifica narrativas desse gênero na ordem de textos, que podem ser expressão da cultura escrita e estar presentes também em culturas de oralidade. ${ }^{19} \mathrm{Como}$ construções históricas em determinado momento histórico, os textos mitológicos pressupõem autores e autoras com determinados interesses comunicativos. Uma das finalidades principais de tais narrativas é a intervenção social para instaurar a ordem social (nomia), os sentidos originários, a retroalimentação de estruturas comunitárias estabelecidas, com eterno retorno ao illud tempus, o tempo originário da narrativa instituidora de sentido. ${ }^{20}$ Quando se levanta a pergunta: o que é "histórico" no mito, a resposta primeira dever ser: o mito surgiu em determinado momento histórico. Nisso e não no seu conteúdo, muitas vezes de natureza fictícia ou lendária, reside a sua dimensão histórica. É necessário fazer a distinção fundamental entre "mundo do texto" e "mundo dos autores", conforme preconizado por Paul Ricoeur. ${ }^{21}$ Quando se aplica esse conceito a textos bíblicos, é evidente que há uma tensão em uma escala maior, porque pela acepção do senso comum quanto ao termo "mito" estaríamos lidando com invenções, lendas, inverdades etc., o que colocaria em xeque a verdade dos textos bíblicos. Os mitos, muitas vezes, são construídos com materiais distintos, incluindo elementos históricos quanto a personagens, lugares, acidentes geográficos etc., podendo esses ser aproveitados para fins de reconstrução histórica. Mas para isso, quando na abordagem crítico-histórica de um texto bíblico se trabalha com esse conceito, é importante passar cada elemento do referido texto pelo viés da crítica e da dúvida quanto à dimensão histórica de elementos do conteúdo, mantendo sempre no

${ }_{17}$ GUNKEL, Hermann. Genesis. Göttingen: Vandenhoeck \& Ruprecht. 1901.

18 Acerca dessas questões ver DIBELIUS, Martin. Die Formgeschichte des Evangeliums. 6. ed. Tübingen, 1971 e BULTMANN, Rudolf. Demitologização: coletânea de ensaios. Trad. Walter Altmann e Luís M. Sander. São Leopoldo: Sinodal, 1999.

19 Ver ARMSTRONG, Karen. Uma histórica do mito. Rio de Janeiro: Cia das Letras, 2005.

${ }^{20}$ Maiores detalhes em REIMER, 2017, p. 89-105, com indicação de bibliografia.

${ }^{21}$ RICOEUR, Paul. O conflito das interpretações: ensaios de hermenêutica. Trad. M. F. Sá Correa. Porto: Rés, 1988. 
horizonte da análise a pergunta pela finalidade original do referido corpo literário em seu contexto histórico originário.

Tal procedimento analítico, devidamente controlado por passos metodológicos, situa pesquisador e pesquisadora e sua pesquisa no campo heurístico. ${ }^{22}$ Outros elementos como a estética (a pergunta pelo belo) e a política (a pergunta pelo que é bom ou funcional) ${ }^{23}$ podem perfeitamente estar presentes no trabalho exegético, mas não devem obstruir o percurso heurístico na busca pela resposta à pergunta: o que, afinal, é verdadeiro? O que é histórico? Para tal, manter a distinção metodológica e a classificação dos resultados é componente fundamental de procedimentos histórico-críticos. Sobre o método histórico-crítico podemos, em suma, dizer com Wegner ${ }^{24}$ :

É um método histórico, em primeiro lugar, porque lida com fontes históricas que, no caso da Bíblia, datam de milênios anteriores a nossa era. Em segundo lugar, porque analisa estas mesmas fontes dentro de uma perspectiva de evolução histórica, procurando determinar os diversos estágios da sua formação e crescimento, até terem adquirido sua forma atual. E, em terceiro lugar, porque se interessa substancialmente pelas condições históricas que geraram estas fontes em seus diversos estágios evolutivos.

Procuramos, a seguir, apresentar alguns passos metodológicos para uma exegese histórico-crítica que considera também elementos interdisciplinares.

\section{Passos metodológicos}

A exegese histórico-crítica e social de um texto bíblico consiste de um conjunto de passos metodológicos que devem ser exercitados na pesquisa. Aqui faremos apontamentos basilares, indicando para discussões alguma referência a textos bíblicos e suas interpretações.

\section{Tradução}

No que tange a textos do Novo Testamento, recomenda-se tomar por base o Novum Testamentum Graece, de Nestle e Aland ${ }^{25}$, e para o Antigo Testamento, a Bíblia Hebraica Stuttgartensia ${ }^{26}$. Fundamentais são os conhecimentos gramaticais adquiridos ao longo dos anos e o acesso a dicionários e concordâncias para o trabalho preliminar de tradução.

22 Ver RIBEIRO, Osvaldo Luiz. Viver hermeneuticamente no mundo: pragmática como ação humana intencional e situada. Caminhos, Goiânia, v. 7, n. 1, p. 105-120, jan./jun. 2009.

23 Ver MORIN, E.; BRIGITTE-KERN, A. Terra-Pátria. 5. ed. Porto Alegre: Sulinas, 2005. p. 77, que desenvolvem a relação entre heurística, estética e política como fundantes do paradigma moderno.

24 WEGNER, Uwe. Exegese do Novo Testamento: manual de metodologia. São Leopoldo: Sinodal; São Paulo: Paulus, 1998. p.17.

25 NESTLE; ALAND, 1994.

${ }^{26}$ BIBLIA HEBRAICA STUTTGARTENSIA. Editio tertia emendate opera W. Rudolph et H. P. Rüger. Stuttgart: Deutsche Bibelgesellschaft, 1987. 
No esforço da tradução, a escolha das palavras é significativa para a interpretação e compreensão do texto, sendo que as traduções em português ou em outras línguas muitas vezes evidenciam pressupostos teológicos, históricos e ideológico-hermenêuticos. Por isso deve-se permanecer o mais próximo do texto original, com seu fluxo narrativo, muitas vezes estranho para nós em outro contexto cultural e linguístico. $\mathrm{O}$ cotejamento das traduções no vernáculo podem ser um apoio, mas não devem ser o fator decisivo na tradução de certos termos.

\section{Análise textual}

Este passo metodológico na análise de um texto consiste basicamente em perceber se existem diferenças entre os vários manuscritos que transmitiram o texto e compreender as mesmas, para então poder avaliar as variantes existentes e decidir por uma delas, como sendo a que apresenta maior probabilidade de corresponder ao texto original ${ }^{27}$. O pressuposto, como na tradução, é o conhecimento da língua grega, no caso de textos do Novo Testamento, e da língua hebraica, no caso de textos do Antigo Testamento, bem como de uma boa experiência na lide com o aparato crítico, que contém os sinais de alteração na transmissão de texto e as siglas dos manuscritos. Como critérios para a decisão, considera-se também o período em que as cópias foram feitas, e por quais regiões os textos tiveram seu percurso de transmissão. Esse é um trabalho minucioso e que demanda muito conhecimento e dedicação, que influenciará na definição da tradução.

Aqui é importante destacar que, em casos de hapaxlegomena, termos que aparecem apenas uma vez, é imprescindível o trabalho extratextual, buscando por outras fontes do mesmo período em que o texto analisado foi escrito, o que deve ser aprofundado, então, no item "Análise histórica e de conteúdo". Sem isso, pode-se incorrer em equívocos históricos e culturais, deixando-se guiar apenas por um "senso comum letrado", apresentado na história da interpretação do texto analisado por meio dos comentários bíblicos principalmente.

\section{Análise literária, da redação e das formas}

A análise literária de um texto visa perceber a delimitação da unidade literária, sua estrutura e as partes que a compõem, sua integridade literária (coesão ou rupturas) e o uso de fontes literárias. ${ }^{28}$ Sua função é clarear se o texto forma uma unidade coesa em termos de conteúdo e de construção. A análise da redação objetiva perceber e compreender a história da redação que o texto carrega em si e os interesses autorais em transmitir e fixar por escrito narrativas e testemunhos que, em muitos casos, circulavam oralmente. A análise da forma da comunicação por escrito ocupa-se em compreender intencionalidades que estão presentes na transmissão por meio de um es-

\footnotetext{
27 WEGNER, 1998, p. 39.

28 WEGNER, 1998, p. 84-89, 122-126.
} 
pecífico gênero literário, bem como o Sitz im Leben no qual a narrativa (oral e ou escrita) foi repetida, transmitida e ensinada, sendo ele considerado como "situação geratriz do texto" 29 . Destacamos que o Sitz im Leben não equivale simplesmente ao contexto histórico em que o texto foi escrito, mas se refere às diversas situações de vida em que ele foi (re)vivido, seja em espaço litúrgico, missionário, de ensino e meditação.

\section{Análise histórica e de conteúdo}

Característica central, neste passo metodológico, é a identificação do "eixo em torno do qual gravita o assunto do texto" 30 , isto é, o tema central e seus subtemas, bem como a capacidade de perceber se esse eixo implica ou mapeia situações de conflitos e perspectivas de solução. Para descobrir esse eixo é preciso considerar o conjunto de uma perícope dentro do contexto literário-estrutural maior, para destacar o caráter sintético-integrativo das partes do conjunto literário em análise. ${ }^{31}$

O trabalho de análise semântica dos termos principais dentro da perícope é fundamental para o seu entendimento. Aqui se recorre à consulta a dicionários, verbetes, monografias e artigos acadêmicos e obras gerais sobre os temas.

$\mathrm{Na}$ busca pela reconstrução do lugar histórico de surgimento do texto e de sua transmissão originária, é importante desvendar aspectos geopolíticos ou aspectos socioculturais do entorno do texto em estudo. Isso, contudo, não deve ser uma imposição metodológica, mas o próprio texto, com seu "eixo" temático ou gênero literário deve demandar tais estudos. Por vezes haverá a necessidade de abordagens mais de cunho jurídico, quando, por exemplo, se tratar de um texto sobre a lei da hospitalidade (Jz 19) ou a lei do levirato (Rute) ou ainda o perdão de dívidas (Dt 15.1-11; Lv 25.35-38; Mt 6.12; 18.23-35) ${ }^{32}$. O tipo de texto e seu conteúdo haverão de demandar os instrumentos de pesquisa histórica a serem utilizados.

Por isso, mesmo que o método histórico-crítico não contemple em suas premissas e seus pressupostos teóricos alguns intrumentais e categorias analíticos, como, p. ex., gênero, para analisar relações específicas de poder entre homens e mulheres em quaisquer sociedades e culturas patriarcais, ele não impede seu uso..$^{33}$ Aliás, exige-o,

29 WEGNER, 1998, p. 172; ver também BERGER, Klaus. As formas literárias do Novo Testamento. Trad. Fredericus A. Stein. São Paulo: Loyola, 1998. Para análise de textos específicos, essa obra de Berger será de grande valia.

30 WEGNER, 1998, p. 260.

31 Ver as informações em WEGNER, 1998, p. 259-269.

32 Acerca dos aspectos jurídico-legais a serem abordados em tais pesquisas, com utilização também do método histórico-crítico, ver REIMER, Haroldo; RICHTER REIMER, Ivoni. Tempos de Graça: o Jubileu e as Tradições Jubilares na Bíblia. São Leopoldo: CEBI; Sinodal; São Paulo: Paulus, 1999.

33 As contribuições metodológicas acerca da categoria analítica de gênero, utilizada junto com os passos metodológicos histórico-críticos, estão bem elaboradas e exercitadas em SCHÜSSLER FIORENZA, Elisabeth. Caminhos da Sabedoria: uma introdução à interpretação bíblica feminista. Trad. Monika Ottermann. São Bernardo do Campo: Nhanduti, 2009; SCHOTTROFF, Luise; SCHROER, Silvia; WACKER, Marie-Theres. Exegese Feminista: resultados de pesquisas bíblicas a partir da perspectiva de mulheres. Trad. Monika Ottermann. São Leopoldo: Sinodal; CEBI; São Paulo: ASTE, 2008. Um exercício dessa interdisciplinaridade que o método histórico-crítico permite pode ser lido em RICHTER REIMER, 
a fim de melhor compreender o texto em seu contexto e conteúdo, bem como a sua história interpretativa. Trata-se, pois, de processos de problematização e complexificação de pesquisas, no esforço de visibilizar aquelas e aqueles que são historicamente inviabilizados pelas narrativas, não raras vezes tendentes a empoderar a perspectiva patriarcal. Da mesma forma, mesmo que o método não pressuponha referenciais teóricos da narratologia ${ }^{34}$, a exegese de textos pode ser com eles enriquecida, seja na análise de personagens, das presenças/ausências de vozes/palavras, bem como nas dissonâncias ou plurivocidades de enunciados num mesmo texto.

Assumimos, portanto, que os passos metodológicos histórico-críticos podem absorver contribuições oriundas de outras áreas ou campos de conhecimento, de forma a contribuir mais profunda, crítica e interdisciplinarmente com a exegese de textos bíblicos.

\section{Análise teológica}

Todo o trabalho exegético de cunho histórico-crítico incluirá, para seu uso e finalidade no campo da Teologia, uma análise das projeções ou propostas teológicas nos respectivos textos. Trata-se de perceber e compreender como o texto em estudo fala sobre Deus e sua ação no mundo. Esses aspectos teológicos, dentro da metodologia proposta, devem ser lidos como expressão comunicativa dos textos em estudo para dentro do seu contexto originário. Trata-se aqui não de simplesmente elencar ou pinçar tais elementos teológicos como elementos funcionais a teorias ou doutrinas teológicas correntes na atualidade, mas buscar verificar as prováveis intencionalidades comunicativas em termos de intervenção social por meio dos referidos textos em seu contexto. A partir daí pode-se inferir em sua relevância e atualidade para hoje, ou não.

Dentro dessa lógica, é importante levantar a pergunta se o enunciado teológico no respectivo texto apresenta elementos de libertação ou elementos que configurem estratégias de dominação e de subjugação. Aqui obviamente estaremos entrando no campo das hermenêuticas, que têm suas premissas e pressupostos, por vezes sintonizados com definições de determinados argumentos religiosos ou eclesiásticos. $\mathrm{O}$ cuidado que se deve ter é não subordinar o trabalho histórico-crítico e social a esses pressupostos teológicos ou dogmáticos!

\section{Conclusão}

Apresentamos alguns resultados da pesquisa realizada sobre o método histórico-crítico, tecendo algumas considerações históricas, com destaque a alguns protagonistas na construção desse método, para situar seu contexto e desenvolvimento. Também apresentamos sinteticamente alguns apontamentos sobre passos metodológi-

Ivoni; SOUZA, Carolina Bezerra de. Mulheres nas Cenas Finais do Evangelho de Marcos: Narrativa, Discurso e Teologia. Perspectiva Teológica, Belo Horizonte, v. 51, p. 133-148, 2019.

34 Ver obra básica de MARGUERAT, Daniel; BOURQUIN, Yvan. Para ler as narrativas bíblicas: iniciação à análise narrativa. Trad. Margarita Oliva. São Paulo: Loyola, 2009. 
cos de uma exegese histórico-crítica. Buscamos demonstrar como o método contribui para o descortinamento e a compreensão de textos bíblicos, destacando sua relevância para a análise textual, redacional, literária e histórica, e defendemos que ele tem abertura para trabalhos interdisciplinares. Isso, contudo, só é possível por meio da própria abertura da/o exegeta que busca por esse descortinamento de realidades, na medida em que o método convida a adentrar o texto para compreender o mundo em que foi escrito, abre horizontes interpretativos e teológicos, pois situa o texto em seu contexto religioso, geopolítico, econômico e sociocultural.

Compreendemos que o trabalho da exegese histórico-crítica deve situar-se fundamentalmente no campo heurístico, isto é, na busca intensa por aquilo que é a dimensão histórica. Hermeneuticamente é vital não aprisionar o texto a uma "verdade" preestabelecida, geralmente de cunho dogmático e sobreposta ao texto. O trabalho metodológico científico não prescinde da decisão hermenêutica e teológica no processo da interpretação. Assim, mesmo descobrindo o mundo do texto, em detalhes exegéticos significativos, a opção da/o exegeta ainda pode retroceder aos pressupostos desenvolvidos em determinado contexto teológico, afirmando-os mesmo contra o texto e os descortinamentos possibilitados por meio do método histórico-crítico.

Neste estudo foi possível perceber que a metodologia histórico-crítica e social contribui para a percepção de que a materialidade e a objetividade devem estar no horizonte do trabalho exegético e histórico-crítico, no sentido de que os próprios textos bíblicos, embora sempre imbuídos de intencionalidades teológicas, devem ser depurados para serem tomados como fontes adicionais para a reconstrução histórica. Nos procedimentos metodológicos existem sempre razões de ordem hermenêutica que se interpõem ou sobrepõem aos resultados. No fundo, o dilema entre a política e a heurística não está resolvido, continuando a ser um campo de tensão em todos os trabalhos nesta área do conhecimento.

O método histórico-crítico foi sendo forjado e aplicado em meio a conflitos e tensões de ordem institucional. O dilema continua no presente não só do ponto de vista dos seus críticos, mas também de seus usuários e suas usuárias. Para uma efetiva reconstrução histórica dos textos sagrados importa fazer a leitura heurística que supera as limitações político-institucionais e ideológico-culturais. Isso pode abrir portas e horizontes para um mais significativo conhecimento histórico e crítico de nossas próprias tradições, em atitude ecumênica com tradições das quais também procedemos.

\section{Referências}

ARMSTRONG, Karen. Uma histórica do mito. Rio de Janeiro: Cia das Letras, 2005. BERGER, Klaus. As formas literárias do Novo Testamento. Trad. Fredericus A. Stein. São Paulo: Loyola, 1998.

BIBLIA HEBRAICA STUTTGARTENSIA. Editio tertia emendate opera W. Rudolph et H. P. Rüger. Stuttgart: Deutsche Bibelgesellschaft, 1987.

BULTMANN, Rudolf. Demitologização: coletânea de ensaios. Trad. Walter Altmann e Luís M. Sander. São Leopoldo: Sinodal, 1999.

CROATTO, José Severino. As Linguagens da Experiência Religiosa: uma introdução à fenomenologia da religião. Trad. Carlos M. V. Gutiérrez. São Paulo: Paulinas, 2001. 
DARWIN, Charles. A origem das espécies. Trad. Eduarco Fonseca. São Paulo: Hemus, [s.d.]. DETIENNE, Marcel. A invenção da mitologia. Trad. André Telles e Gilza Gama. Rio de Janeiro: José Olympio; Brasília: UnB, 1998.

DIBELIUS, Martin. Die Formgeschichte des Evangeliums. 6. ed. Tübingen, 1971.

GUNKEL, Hermann. Genesis. Göttingen: Vandenhoeck \& Ruprecht, 1901.

FINKELSTEIN, Israel; SILBERMAN, Neil Asher. A Bíblia não tinha razão. Trad. Tuca Magalhães. São Paulo: A Girafa, 2003.

FITZMYER, Joseph A. A interpretação da Escritura: em defesa do método histórico-crítico. São Paulo: Loyola, 2011.

FUNARI, Pedro Paulo. Os historiadores e a cultura material. In: PINSKY, Carla Bassanezi (Org.). Fontes históricas. 2. ed. São Paulo: Contexto, 2010. p. 81-110.

KAEFER, José Ademar. A Liberdade como condição para a Paz! As Cartas de El-Amarna e o contexto sociopolítico do Sul de Canaã. Caminhos, Goiânia, v. 17, n. 2, p. 791-808, maio./ago. 2019. Disponível em: <http://seer.pucgoias.edu.br/index.php/caminhos/article/view/7289/4173>. Acesso em: 19 set. 2019.

MARGUERAT, Daniel; BOURQUIN, Yvan. Para ler as narrativas biblicas: iniciação à análise narrativa. Trad. Margarita Oliva. São Paulo: Loyola, 2009.

MORIN, Edgar; BRIGITTE-KERN, A. Terra-Pátria. 5. ed. Porto Alegre: Sulinas, 2005.

NESTLE, Eberhard e Erwin; ALAND, Barbara e Kurt (Orgs.). Novum Testamentum Graece. 27. rev. Aufl., 2. Druck. Stuttgart: Deutsche Bibelgesellschaft, 1994.

REIMER, Haroldo. O Antigo Israel: história, textos e representações. São Paulo: Fonte; Anápolis: Ed. da UEG, 2017.

REIMER, Haroldo; RICHTER REIMER, Ivoni. Tempos de Graça: o Jubileu e as Tradições Jubilares na Bíblia. São Leopoldo: CEBI; Sinodal; São Paulo: Paulus, 1999.

RIBEIRO, Osvaldo Luiz. Viver hermeneuticamente no mundo: pragmática como ação humana intencional e situada. Caminhos, Goiânia, v. 7, n. 1, p. 105-120, jan./jun. 2009. Disponível em: $<$ http://seer.pucgoias.edu.br/index.php/caminhos/article/view/1199/845>. Acesso em: 15 set. 2019.

RICHTER REIMER, Ivoni; SOUZA, Carolina Bezerra de. Mulheres nas Cenas Finais do Evangelho de Marcos: Narrativa, Discurso e Teologia. Perspectiva Teológica, Belo Horizonte, v. 51, p. 133-148, 2019.

RICOEUR, Paul. O conflito das interpretações: ensaios de hermenêutica. Trad. M. F. Sá Correa. Porto: Rés, 1988.

RODRIGUES, Gabriella Barbosa. Arqueologia biblica: um estudo de narrativas e discursos acerca de sua história como disciplina. Campinas, 2011.

RODRIGUES, Gabriella Barbosa; FUNARI, Pedro Paulo A. Considerações sobre a trajetória inicial da arqueologia bíblica. Mosaico, Goiânia, v. 2, n. 2, p. 95-101, jul./dez. 2009.

SCHOTTROFF, Luise; SCHROER, Silvia; WACKER, Marie-Theres. Exegese Feminista: resultados de pesquisas bíblicas a partir da perspectiva de mulheres. Trad. Monika Ottermann. São Leopoldo: Sinodal; EST; CEBI; São Paulo: ASTE, 2008.

SCHÜSSLER FIORENZA, Elisabeth. Caminhos da Sabedoria: uma introdução à interpretação bíblica feminista. Trad. Monika Ottermann. São Bernardo do Campo: Nhanduti, 2009.

TROELTSCH, Ernst. Über historische und dogmatische Methode in der Theologie. In: Theologie und Wissenschaft. Theologische Bucherei, Munique, v. 40, p. 105-127, 1971.

VOLKMANN, Martin; DOBBERAHN, Friedrich Erich; CÉSAR, Ely Éser Barreto. Método Histórico-crítico. São Paulo: CEDI, 1992.

WEGNER, Uwe. Exegese do Novo Testamento: manual de metodologia. São Leopoldo: Sinodal; São Paulo: Paulus, 1998. 